Bangladesh J. Bot. 50(3): 955-961, 2021 (September) SpecialＤOI: https://doi.org/10.3329/bjb.v50i5.56450

\title{
CHANGES OF SOIL MOISTURE DURING APPLE GROWTH BASED ON TVDI INDEX
}

\author{
Hui Kong ${ }^{1 *}$ AND DAN Wu ${ }^{1}$ \\ Institute of Land Engineering and Technology, Shaanxi Land Engineering \\ Construction Group Co. Ltd., Xi'an 710075, China
}

Keywords: TVDI, Soil moisture, Orchard, MODIS, Consistency

\begin{abstract}
Based on MODIS data, soil moisture data and field survey data from 2014 to 2018, the consistency of temperature vegetation drought index (TVDL), normalized vegetation water content index (NDWL), vegetation water supply index (VSWI) and soil moisture at $15 \mathrm{~cm}$ depth (SM) in apple growth in Fuxian county was investigated. Results showed that the spatial and temporal consistency between VSWI and SM calculated by the enhanced vegetation index (EVI) was best; the sensitivity of remote sensing indexes to soil moisture was different in different apple growth stages. The sensitivity of VSWI was the most obvious in different growth stages, and the sensitivity of soil moisture was higher than that of germination, flowering, fruit expansion and maturity. The research findings were consistent with the law of water demand in different growth stages of apple in Fuxian county and the characteristics of precipitation and drought in Fuxian county. The present results could provide a reference for soil moisture monitoring of apple growth by remote sensing.
\end{abstract}

\section{Introduction}

As the world's largest producer and consumer of apples, China accounts for more than 40 per cent of the world's apple production. Fuxian county of Shaanxi Province located in the north of Weihe drought source is the main production area of high-quality apples in China (Barrett $e t$ al. 2009). Apple industry is the main driving force to promote the economic development of the region. However, Fuxian county is an arid and semi-arid area, with obvious continental monsoon consumption during the whole growth period of apple trees, and the backward irrigation method in climate, lack of water resources and uneven precipitation all year round. Due to the high-water most orchards, the water utilization rate is low (Verhoest et al. 2008), so the drought disaster seriously affects the apple yield and quality in this area. On the other hand, global warming intensifies the threat of drought to apples (Yu and Zhao 2008), and there is an urgent need to carry out apple drought monitoring work. Previous studies have made great breakthroughs in crop remote sensing drought monitoring, and developed a series of remote sensing indicators for crop drought monitoring, such as temperature vegetation drought index TVDI, which is related to crop canopy temperature (Baghdadi et al. 2004). The normalized vegetation water index (NDWI), which is related to the water content of crop canopy (Burges 1998), and the vegetation water supply index (VSWI), comprehensively reflects crop form, vegetation greenness and canopy temperature (Trudel et al. 2012).

The present study took MODIS reflectivity product MOD09A1, land surface temperature product MOD11A2 and land cover number MCD12Q1 as remote sensing data sources, combined with soil moisture data and field survey data, and took Fuxian county as the study area to analyze the consistency of remote sensing drought index TVDI (Holah et al. 2006), NDWI, VSWI and soil moisture in Apple Region. In addition, the sensitivity to drought in different growth stages of

*Author for correspondence: $<2013127006 @$ chd.edu.cn>. ${ }^{1}$ Key Laboratory of Degraded and Unused Land Consolidation Engineering, the Ministry of Natural Resources, Xi'an 710075, China. 
apples was investigated to evaluate the applicability of different remote sensing drought indicators, so as to provide a simple and effective monitoring method for drought monitoring of apples (Ding et al. 2011).

\section{Materials and Methods}

Located in the central part of Shaanxi Province $\left(35^{\circ} 21\right.$ '09 " 36 $04^{\circ} 12^{\prime \prime}$ N, $109^{\circ} 18$ '14 " 109 $45^{\prime} 47^{\prime \prime}$ E) and the south of Yan 'an, Fuxian county is located in the arid source gully area of Weibei, with an average altitude of $1100 \sim 1200 \mathrm{~m}$. The terrain is higher in the north and lower in the south, higher in the east and lower in the west, and belongs to the continental monsoon climate of the north temperate zone. The annual average precipitation is $623.6 \mathrm{~mm}$, concentrated in June to September (Joseph et al.2011). The average annual temperature is about $9.9^{0} \mathrm{C}$, the temperature difference between day and night is large, and the sunshine is sufficient, which is conducive to the synthesis, accumulation and operation of photosynthetic substances in apples, making it a suitable area for growing high-quality apples in the world. The groundwater resources in Fuxian county are poor (Lievens and Verhoest 2011), with an average annual evaporation of $1560 \mathrm{~mm}$, which has a large gap with precipitation, unbalanced water budget and frequent drought disasters (Wang et al. 2004). The industry in Fuxian county is dominated by apple industry. As of 2019, the cultivated land area of Fuxian county is about 640,000 mu, among which the apple planting area is 500,000 $\mathrm{mu}$, accounting for 7,800 cultivated land area. The apple needs a lot of water. Drought is the main natural disaster that restricts the development of apple industry in Fuxian county (Fig. 1).

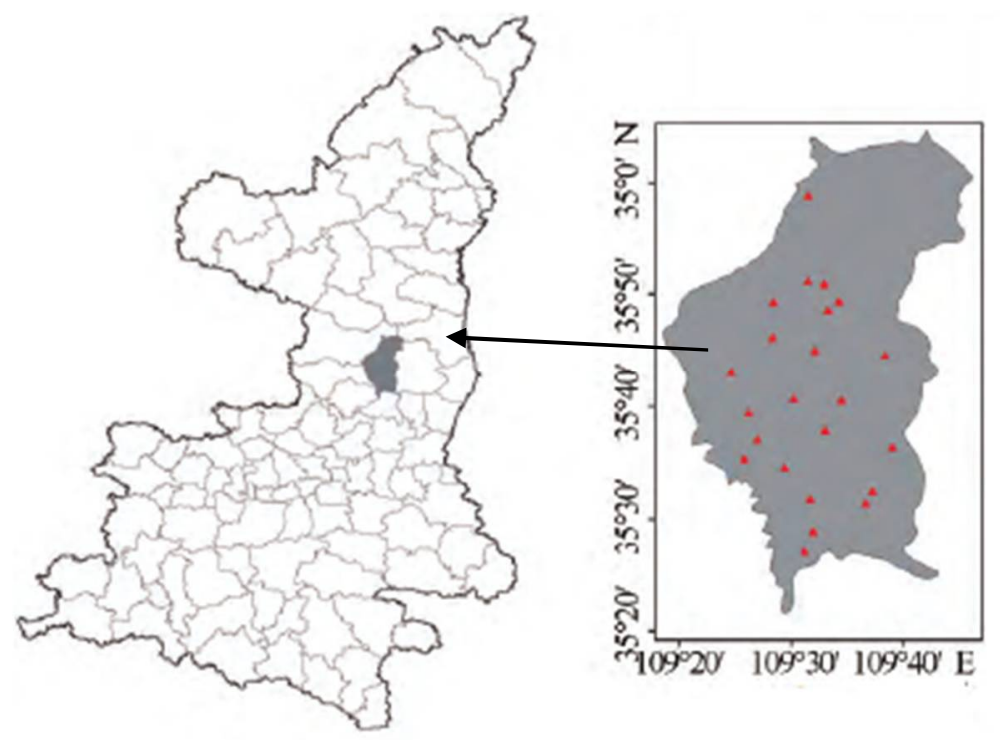

Fig.1. Location of Fuxian county in Shannxi province and distribution of apple samples.

The data sources used in this study mainly include MODIS data, soil moisture data, field survey data, etc. In order to ensure that the research period is the main growth period of apple and avoid the influencing factors of drought disaster in the study area in recent years, the MODIS land surface reflectance data set MOD09A1 and land surface temperature data set MOD11A2 from 2014 to 2018 were determined. The data of the 81st day and the 305th day (from March to October) were extracted to calculate the drought index by remote sensing every year. MODIS data 
were derived from the geospatial data cloud platform (http://www.gscloud.cn/). The temporal resolution of MOD09A1 and MOD11A2 datasets was 8 days, and the spatial resolution was $500 \mathrm{~m}$ (MOD09A1) and 1km (MOD11A2), respectively. MODIS land cover product MCD12Q1 was used in the process of land surface temperature reconstruction, with a resolution of $500 \mathrm{~m}$.

MODIS data processing mainly includes Mosaic, reprojection, clipping, elimination of invalid values (including filled pixels and poor-quality pixels) and reconstruction of deleted values. Among them, for different data sets, the culled data and reconstruction methods are different. The surface reflectance data set MOD09A1 has some filling values. In order to extract the effective data of MOD09A1 images, the filling values were removed first, and then the average values of pixels with the same land use type within the range of pixel $9 * 9$ to be filled were used to fill them, and the enhanced vegetation index (EVI) and normalized vegetation index (NDVI) were calculated (Hosseini et al. 2015) form EVI and NDVI sequence sets from 2014 to 2018 . There are large areas of filling value or poor quality pixels (such as cloud coverage pixels) in MOD11A2 land surface temperature data, which will lead to a large number of missing research data and affect the experimental results. Therefore, it is necessary to reconstruct the deleted images. The reconstruction method of MODIS land surface temperature data proposed by (Tong et al. 2014) was adopted. The principle is that the land surface temperature of adjacent pixels of the same vegetation type is similar. In order to ensure the same temporal and spatial resolution, the reconstructed MOD11A2 LST data were sampled to 500m using bilinear interpolation method. The average method was used to synthesize the soil moisture dataset with a time resolution of $8 \mathrm{~d}$, and the sample was lowered to $500 \mathrm{~m}$.

The physiological state and growth status of crops are closely related to the development of drought. Therefore, crop morphology, greenness, canopy temperature, water content and cell fluid concentration can be used to monitor crop drought status. NDVI, Vegetation Condition Index (VCI) and other indexes only consider crop morphology and greenness, and are prone to saturation phenomenon in high vegetation cover areas (Gherboudj et al. 2011). TCI only considers crop canopy temperature, and is not suitable for large-scale monitoring value. NDWI is directly related to canopy water content, and some studies have shown that NDWI is more sensitive to drought than NDVI. However, VSWI and TVDI comprehensively consider crop form, green degree and canopy temperature, which are sensitive to crop planting structure and can avoid the problem of over-saturation in high vegetation cover areas. Therefore, three remote sensing drought indexes, VSWI, TVDI and NDWI, were selected for the present study.

(i) Temperature Vegetation Dryness Index (TVDI) was first proposed by (Sandholt et al. 2002). The normalized vegetation index (NDVI) and land surface temperature (LST) (Jin et al. 2015), two factors representing vegetation growth conditions, were considered to construct the NDVILST feature space, and the corresponding vegetation canopy temperature or soil temperature information was counted in different vegetation index ranges. The calculation formula is as follows:

$$
T V D I(N D V I)=\frac{L S T-L S T_{\min }}{L S T_{\max }-L S T_{\min }}
$$

Wherein, $a_{1}, b_{1}, a_{2}$ and $b_{2}$ are respectively the coefficients of dry-side and wet-side equations fitted by vegetation index and LST feature space. The value range of TVDI is $[0,1]$. The higher the value is, the lower the soil moisture is and the higher the drought degree is.

$$
\begin{aligned}
& \mathrm{LST}_{\text {max }}=a_{1}+b_{1} * \mathrm{NDVI} \\
& \mathrm{LST}_{\text {min }}=a_{2}+b_{2} * \mathrm{NDVI}
\end{aligned}
$$

(ii) Vegetation Supply Water Index and gt; VSWI), based on the abnormal physiological characteristics of vegetation in drought stress, proposed that VSWI is suitable for vegetation 
covered areas and has better response to drought in areas with high vegetation cover. Therefore, the enhanced vegetation index EVI was used in the calculation of VSWI in this study, and the results were compared with those calculated by NDVI. VSWI based on NDVI and EVI is denoted as VSWI(NDVI) and VSWI(EVI) respectively, and the calculation formula is:

$$
\begin{aligned}
\operatorname{VSWI}(\mathrm{NDVI}) & =\frac{\mathrm{NDVI}}{\mathrm{TS}} * 100 \\
\operatorname{VSWI}(\mathrm{EVI}) & =\frac{\mathrm{EVI}}{\mathrm{TS}} * 100
\end{aligned}
$$

Where, TS represents the surface temperature in Kelvin (K), and the smaller the VSWI value is, the more seriously affected by drought; otherwise, it means the less affected by drought or not affected by drought.

(iii) Normalized Difference Water Index (NDWI) was constructed by using $860 \mathrm{~m}$ and 1240 $\mathrm{nm}$ to retrieve vegetation moisture content. The relationship between the combination of MODIS 7 bands and vegetation water content was studied (Kim et al.2013). The results showed that the NDWI calculated by MODIS 7 band (2105 v2155 nm) was the most effective for the inversion of vegetation canopy water, which was less affected by soil background and other factors. Therefore, the seventh band and the second band were used to calculate NDWI in this paper.

$$
\mathrm{NDWI}=\frac{\rho_{2}-\rho_{7}}{\rho_{2}+\rho_{7}}
$$

$\rho_{2}$ and $\rho_{7}$ are the reflectance of the second and seventh band of MODIS. The smaller the NDWI value is, the lower the water content of the canopy is, and the greater the possibility of drought or the more seriously affected by drought is.

\section{Results and Discussion}

Figure 2 showed the temporal variation trend of the three remote sensing drought indexes and soil moisture, and the consistency of the remote sensing indexes and soil moisture can be analyzed from the time dimension. On the whole, VSWI, NDWI and soil moisture (SM) showed similar variation patterns, while TVDI and SM showed opposite variation patterns to some extent. Correlation analysis showed that there was a significant positive correlation between VSWI, NDWI and SM, and a significant negative correlation between TVDI and SM. The absolute value of correlation coefficients was listed as

$$
\mathrm{r}(\mathrm{NDWI})>\mathrm{r}(\mathrm{VSWI}(\mathrm{EVL}))>\mathrm{r}(\mathrm{VSWI}(\mathrm{NDVL}))>\mathrm{r}(\mathrm{TVDI}(\mathrm{EVI}))>\mathrm{r}(\mathrm{TVDI}(\mathrm{NDVI}))
$$

The correlation for NDWI was 0.695 and for VSWI(EVI) was 0.615 .

VSWI, NDWI and SM showed obvious changes within one year: the values increased first and then decreased, and there was a peak in one year, appearing roughly in June to August. This feature is roughly consistent with the variation of precipitation and temperature in Fuxian county (Fig. 2). At the same time, the larger was VSWI, the smaller the degree of drought, the larger was NDWI, and the higher was the water content of vegetation. The peak value of VSWI and NDWI from June to August might be caused by two aspects: one is caused by the growth law of apple tree itself; The peak of VSWI and NDWI from June to August was consistent with the growth law of apple. The peak of VSWI and NDWI from June to August was consistent with the growth law of apple. Secondly, it is related to the climate characteristic of rainy summer in Fuxian county. Precipitation from June to August accounted for about 6,000 of the annual precipitation. The probability of drought in summer was less than that in spring, and the values of VSWI and NDWI were higher in summer. The change characteristics of TVDI 1 year generally decreased first and then increased, contrary to the changes of VSWI, NDWI and SM, there was only one trough in 
one year, and the time range of occurrence was roughly from June to August. Due to the characteristics of high temperature in summer of typical continental monsoon climate in the study area, the temperature in July was the highest in the whole year, and water evaporation intensified, leading to a small trough in soil moisture, VSWI and NDWI around July, which was more obvious in July 2014.

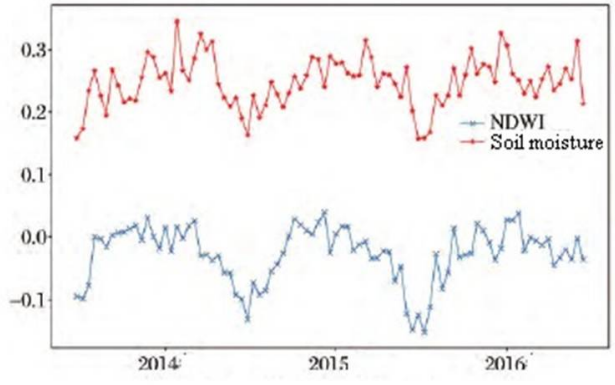

(a)

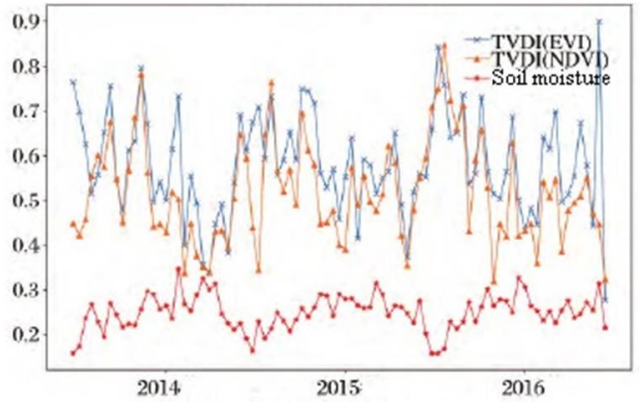

(b)

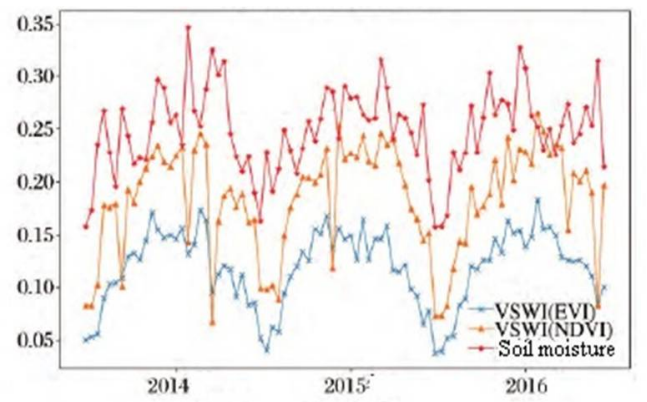

(c)

Fig. 2. Trends of NDWI, VSWI, TVDI and SM from 2014 to 2016. (a) The trend of NDVI and SM (b) The trend of VSWI and SM (c) The trend of TVDI and SM.

The response of vegetation to soil moisture is a complex process, and the sensitivity of vegetation to soil moisture is different in different growth stages. Simultaneity NDWI, delayed 3phase VSWI and delayed 1-phase TVDI and SM were used for sensitivity analysis, and the results were shown in Fig. 2. During the period of seed expansion and deciduous dormant, the water demand was the highest in the period of new shoot growth, while from May to June, when new shoot growth and young fruit growth occurred, was a sensitive period of water supply. Moreover, there was less precipitation during this period and it was prone to drought. Therefore, apple trees were highly sensitive to the change of soil water (water shortage). Therefore, the remote sensing drought monitoring index based on vegetation growth has a good correlation with soil moisture in this period.

Monitoring indexes and SM was lower during the fruit expanding period (July to September). The reason might be that the growth period of new shoots is the growth period of apple trees, during which the tree growth changes obviously. The apple trees are highly sensitive to water shortage, and water stress can significantly affect the normal growth of apple leaves, branches and trunks, thus affecting the tree growth information (NDVI, EVI, vegetation coverage, LAI and other parameters) obtained from remote sensing images. However, the water demand in the fruit 
expansion period is lower than that in the shoot boom period, which may affect the sensitivity of apple trees to water shortage. Moreover, this period is the fruit growth and development period,

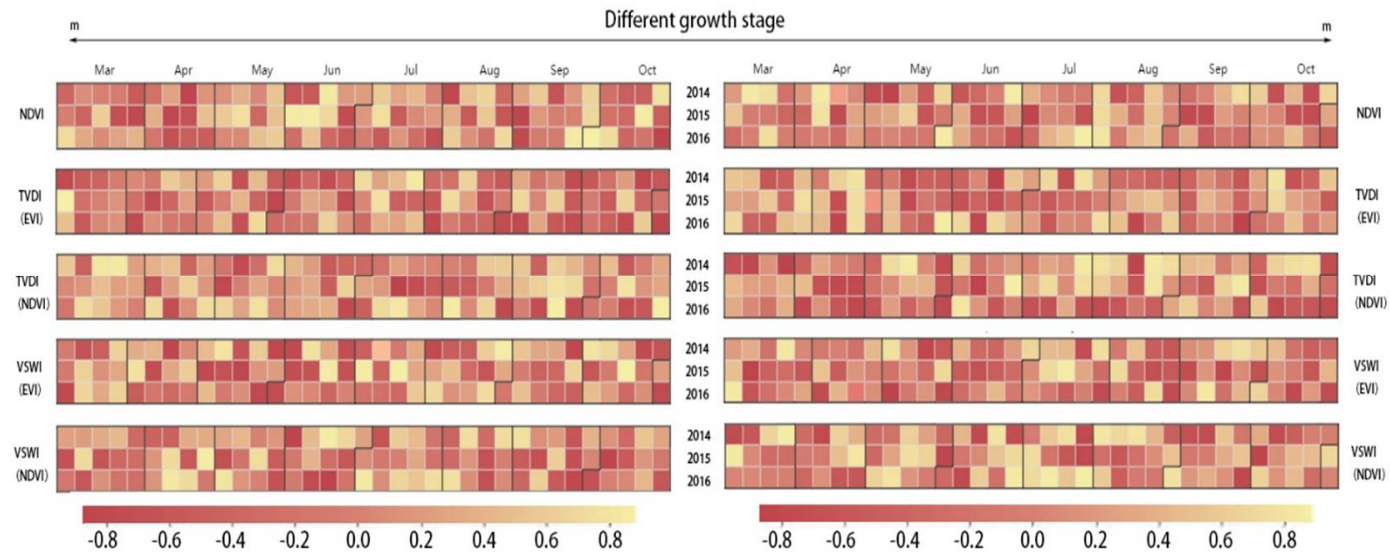

Fig.3. Matrix diagram of the correlation coefficient between remote sensing based drought indices and SM in different growth periods of apple from 2014 to 2016.

Compared with the growing period (April to July), the correlation between drought and water shortage will cause the leaves and fruits to compete for nutrients, resulting in fruit dropping. Therefore, water shortage in this period mainly affects fruit development, which is limited by the spatial resolution of remote sensing. The information obtained by remote sensing image is more about the information of tree leaves and branches, and contains limited fruit information. Therefore, it is unable to capture the growth changes of fruits sensitively, which affects the response of drought index to the change of soil moisture. As a result, the correlation between drought index and SM is weaker than that in the flowering period of shoots (Fig. 3).

\section{Acknowledgements}

The project was supported by a project grant from Shaanxi Land Construction - Xi'an Jiaotong University Land Engineering and Human Settlement Technology Innovation Center Open Fund (2021WHZ0088) and Quick Calculation of Earthwork in Land Consolidation Based on Digital Elevation Model Data (DJNY2019-29) and Land Use Classification of High Spatial Resolution Remote Sensing Image Based on Machine Learning (DJNY2021-32).

\section{References}

Baghdadi N, Gherboudj I, Zribi M, Sahebi M, King C and Bonn F 2004 Semi-empirical calibration of the IEM backscattering model using radar images and moisture and roughness field measurements. Int. J Remote Sensing, 25(18): 3593-3623.

Barrett BW, Dwyer E and Whelan P 2009. Soil moisture retrieval from active spaceborne microwave observations: an evaluation of current techniques. Remote Sensing, 1(3): 210-242.

Burges CJC 1998. A Tutorial on support vector machines for pattern recognition. Data Mining and Knowledge Discovery 2(2): 121-167.

Ding SF, Qi BJ and Tan HY 2011. Review on theory and algorithm of support vector machines. J Univ. Elect. Sci. Technol China 40(1): 2-10.

Gherboudj I, Magagi R, Berg AA and Toth B 2011 Soil moisture retrieval over agricultural fields from multipolarized and multi-angular RADARSAT-2 SAR data. Remote Sens. Environ. 115(1): 33-43. 
Holah N, Baghdadi N, Zribi M., Bruand A and King C 2006. Potential of ASAR/ENVISAT for the characterization of soil surface parameters over bare agricultural fields. Remote Sens. Environ. 96(1): 78-86.

Hosseini M, Mcnairn H, Merzouki A and Pacheco A 2015. Estimation of Leaf Area Index (LAI) in corn and soybeans using multi-polarization C- and L-band radar data. Remote Sens. Environ. 170: 77-89.

Jin X, Yang G, Xu X, Yang H, Feng H and Li Z 2015. Combined multi-temporal optical and radar parameters for estimating LAI and biomass in winter wheat using HJ and RADARSAR-2 Data. Remote Sens. 7(10): 13251-13272.

Joseph AT, Velde RVD, O "Neill, PE, Lang R and Gish T 2011. Effects of corn on C- and L-band radar backscatter: A correction method for soil moisture retrieval. Remote Sens. Environ. 114(11): 2417-2430.

Kim Y, Jackson T, Bindlish R and Hong S 2013. Retrieval of wheat growth parameters with radar vegetation indices. IEEE Geosci. Remote Sens. Letters 11(4): 808-812.

Lievens H and Verhoest NEC 2011. On the retrieval of soil moisture in wheat fields from L-Band SAR based on water cloud modeling, the IEM, and effective roughness parameters. IEEE Geosci. Remote Sens. Letters 8(4):740-744.

Sandholt I, Rasmussen K and Andersen J 2002. A simple interpretation of the surface temperature/vegetation index space for assessment of surface moisture status. Remote Sensing of Environment 79(2-3), 213224.

Tong S, Xia Z, Wang S, Zhang L, Shang K and Chen X 2014. A Spectral angle distance-weighting reconstruction method for filled pixels of the MODIS land surface temperature product. IEEE Geoscience \& Remote Sensing Letters 11(9):1514-1518.

Trudel M, Charbonneau F and Leconte R 2012. Using RADARSAT-2 polarimetric and ENVISAT-ASAR dual-polarization data for estimating soil moisture over agricultural fields. Canadian J. Remote Sens. 38(4):514-527.

Verhoest NEC, Hans L, Wolfgang W, Jess LM and Francesco M 2008. On the soil roughness parameterization problem in soil moisture retrieval of bare surfaces from synthetic aperture radar. Sensors 8(7): 4213-4248.

Wang C, Qi J and Moran 2004. Soil moisture estimation in a semiarid rangeland using ERS-2 and TM imagery. Remote Sens. Environ. 90(2): 178-189.

$\mathrm{Yu} \mathrm{H}$ and Zhao H 2008. New research on multi-class classification algorithm of support vector machines. Computer Engineer. Applications 44(7) :185-189, 212

Zhang R and Ma JW 2009. New progress of support vector machine application in remote sensing data classification. Advan. Earth Sci. 24(5): 555-562. 